\title{
Sykepleiere kan \\ forebygge lekkasje av LAR-legemidler
}

Legemidler som skal redusere sykdom og død blant pasienter som deltar i legemiddelassistert rehabilitering, blir solgt til rusmiddelbrukere. Sykepleiere kan forhindre at dette skjer .

\section{Forfatter}

\section{Anne Bech}

Stipendiat

Nasjonal kompetansetjeneste for samtidig rusmisbruk og psykisk lidelse, Sykehuset Innlandet HF

\section{Nøkkelord}

Legemiddelassistert rehabilitering lekkasje Metadon buprenorfin Sykepleie

Sykepleien 2018 106(69953)(e-69953)

DOI: https://doi.org/10.4220/Sykepleiens.2018.69953

HOVEDBUDSKAP

Lekkasje av legemidlene metadon og buprenorfin (for eksempel Subutex®) til det illegale narkotikamarkedet er en utfordring i de fleste land som tilbyr substitusjonsbehandling ved opioidavhengighet. Formålet med artikkelen er å beskrive eksisterende kunnskap om lekkasje og illegal bruk av LAR-legemidler. Sykepleiere kan forebygge lekkasje av legemidlene ved å ha oppdatert kunnskap om legemidlene, og ved å fokusere på pasienters psykososiale situasjon og tiltak for å stoppe pågående rusmiddelbruk.

\section{Introduksjon}


Substitusjonsbehandling med langtidsvirkende opioider, på norsk kalt legemiddelassistert rehabilitering (LAR), reduserer dødelighet og sykelighet hos pasienter med opioidavhengighet $(1,2)$. Samtidig er lekkasje av substitusjonslegemidlene til det illegale narkotikamarkedet en utfordring i mange land (3-8). Lekkasje er ofte definert som å selge eller gi bort substitusjonslegemidlene til personer legemidlene ikke er ment for. Til tross for at lekkasjeproblematikken ser ut til å være økende, finnes det få systematiske undersøkelser som kan fastslå sikkert hvor stort problemet er (3), og det er store nasjonale forskjeller (9). Det er forsket lite på hvordan sykepleiere kan bidra til å redusere lekkasje av substitusjonslegemidler (10), men generelt er sykepleiere i en ideell posisjon til å forebygge lekkasje av opioider (11). Oppfølging av medikamentell behandling er tradisjonelt en sykepleieoppgave. Sykepleiere har en nøkkelrolle når det gjelder å formidle endringer i pasienters helsetilstand og rusmestring til forskrivende lege (10).

\section{三 «Generelt er sykepleiere i en ideell posisjon til å forebygge lekkasje av opioider.»}

Formålet med artikkelen er å beskrive eksisterende kunnskap om lekkasje og illegal bruk av LARlegemidlene buprenorfin og metadon. Formålet er også å beskrive tiltak sykepleiere bør kjenne til for å kunne forebygge lekkasje. Artikkelen er basert på egen klinisk erfaring og et subjektivt utvalg av aktuell litteratur. Tiltak som er relevante og overførbare til en norsk klinisk kontekst, har vært vektlagt.

\section{Legemiddelassistert rehabilitering}


I Norge er LAR strengt regulert, og ble nasjonalt tilgjengelig fra 1998. Grunnlaget for å sette i gang LAR er opioidavhengighet etter diagnosekriterier gitt i klassifikasjonssystemene ICD-10 og DSM-IV (12). Illegal bruk av opioider som heroin erstattes med daglig peroralt inntak av de langtidsvirkende opioide legemidlene metadon eller buprenorfin. Legemidlene bidrar til stabil opioideffekt, og ved riktig dosering skal pasienten verken være abstinent eller ruspåvirket (1).

\section{KLASSIFIKASJONSSYSTEMENE ICD-10 OG DSM-IV}

I klassifikasjonssystemene ICD-10 og DSM-IV defineres rusmiddelavhengighet som en biopsykososial lidelse med forekomst av flere diagnosekriterier i løpet av de siste 12 månedene. Jevnlig tilførsel av opioider fører til langvarige endringer i sentralnervesystemet som ledsages av

- toleranseøkning for visse opioideffekter

- abstinensreaksjoner ved avbrudd av opioidtilførsel

- endringer i motivasjonsbanene i hjernen

- endringer i stressreguleringen

- svekket overordnet styring gjennom påvirkning av funksjoner i fremre hjernelapp

Av disse fem forholdene anses de tre siste å være det nevrobiologiske grunnlaget for opioidavhengighet.

Kilde: Helsebiblioteket

Ifølge LAR-forskriften er særregulering nødvendig på grunn av bruken av sterkt vanedannende legemidler (13). Både metadon og buprenorfin har stort misbrukspotensial og er ettertraktet i rusmiljøene (5). Andelen LAR-pasienter i Norge som bruker metadon, har gått jevnt nedover de siste årene. I 2016 brukte 38 prosent metadon, 39 prosent monopreparatet buprenorfin, 20 prosent brukte kombinasjonspreparatet Suboxone ${ }^{\circledR}$ og 3 prosent andre opioide legemidler (14). Ved utgangen av 2016 var 7554 pasienter i LARbehandling i Norge (14). 


\section{Illegal bruk av LAR-legemidlene}

Den vanligste misbruksmåten for buprenorfin er at tablett eller film løses opp i vann og injiseres, og buprenorfin gir da en morfinliknende rus. Buprenorfin kan også sniffes, inhaleres/røykes eller tas sublingvalt (under tungen) for å oppnå ruseffekt $(4,8)$. Metadon drikkes eller injiseres. Generelt vurderes buprenorfin å ha lavere potensial for eufori sammenliknet med metadon (8).

\section{三 «LAR-legemidlene brukes illegalt for å oppnå ruseffekt.»}

LAR-legemidlene brukes illegalt for å oppnå

eufori/ruseffekt, vanligvis som en del av

blandingsmisbruk (5). Andre årsaker til illegal bruk er pris og tilgjengelighet (4). Selv om heroin fortsatt dominerer som hovedrusmiddel blant dem som søker seg inn i behandling for opioidavhengighet i Europa, oppgir 20 prosent at hovedrusmiddel er opioider som metadon, buprenorfin eller fentanyl (15), som er et syntetisk opioid som er 100 ganger mer potent enn morfin.

I noen land er substitusjonsbehandling lite tilgjengelig. For personer med etablert opioidavhengighet uten substitusjonsbehandling kan illegal bruk av buprenorfin være et forsøk på å redusere bruk av heroin, eller et forsøk på å selvmedisinere/behandle opioidavhengighet, lindre abstinenssymptomer og redusere skader knyttet til injisering.

Ved slik selvmedisinering kan den illegale bruken ha noen positive effekter (4), og være mindre helseskadelig enn injisering for å oppnå ruseffekt (16). Lengre perioder med selvmedisinering utenfor substitusjonsbehandling kan også skyldes vanskeligheter med å forbli i behandling, ambivalens på grunn av kontrollrutiner i behandlingen eller stigmatisering fra andre i rusmiljøet (17). 
For pasienter i substitusjonsbehandling kan årsaker til illegal bruk av metadon og buprenorfin være utilstrekkelig dosering av LAR-legemidlene (4), eller ønske om ruseffekt.

\section{Lekkasje av LAR-legemidlene}

I Europa er det anslått at 24 prosent av pasientene med substitusjonsbehandling har solgt, byttet eller gitt bort substitusjonslegemidler, mens i Norge er dette anslått til 26 prosent (9).

I Oslo hadde 27 prosent av injiserende rusmiddelbrukere brukt illegale LAR-legemidler siste fire uker, ofte i tillegg til andre rusmidler (16).

Gjersing og Sandøy (18) fant signifikante forskjeller mellom byene i illegal bruk av LAR-legemidler, med forekomst på 13-27 prosent på buprenorfin og 3-15 prosent på metadon.

\section{三 «Det å selge sin medisin er en måte å tjene penger på.»}

Den sterkeste risikofaktoren for at LAR-pasienter skal selge eller gi bort sine LAR-legemidler, er at de selv bruker rusmidler, og spesielt at de injiserer rusmidler $(5,6,8,19)$. Bruk av rusmidler krever penger, og det å selge (deler av) sin medisin er en måte å tjene penger på $(5,6,19-21)$.

Noen trapper ned dosen, enten fordi de ikke trenger hele dosen selv $(6,21)$, eller de lar være å ta forskrevet dose for å oppnå ruseffekt av heroin ved å unngå den blokkerende effekten av buprenorfin (20). Andre motiver kan være å hjelpe en venn eller partner. Det å kunne hjelpe en venn som har abstinenser, blir av rusmiddelbrukere sett på som positivt og moralsk riktig (7), med liten risiko for å bli oppdaget (20). 
Lekkasje kan derfor sees på som forståelig og noe som forventes av pasienter i LAR (20). Det er ikke vanlig å gi bort LAR-legemidler gratis (6). De fleste selger

LAR-legemidler til venner eller personer i sitt rusmiljø, eller bytter til seg andre rusmidler $(6,19)$. Kontakt med rusmiljøet kan også gi økt risiko for lekkasje (5).

\section{三 «Helserisiko ved lekkasje av LAR-legemidler er økt dødelighet og sykelighet.»}

Helserisiko ved lekkasje av LAR-legemidler er økt dødelighet og sykelighet (8), inkludert helseskader på grunn av injisering, som abscesser, infeksjoner, embolier, endokarditt, sepsis, hiv og hepatitt Cinfeksjon (4). Det er bekymringsfullt at lekkasje av LAR-legemidler kan bidra til å utvikle avhengighet hos nye brukere og hos personer som eksperimenterer med illegale rusmidler $(3,4)$.

Lekkasje kan også påvirke befolkningens holdninger til LAR negativt $(8,16)$. Selv om enkelte argumenterer for at lekkasje og illegal bruk er mindre skadelig enn antatt, spesielt hvis heroinbruk er alternativet $(4,16)$, er det et mål å holde lekkasje av LAR-legemidler på et så lavt nivå som mulig (1).

\section{Riktig LAR-legemiddel i riktig dose}


De ulike LAR-legemidlene har sine fordeler og ulemper som sykepleiere må kjenne til. I Norge er buprenorfin førstevalg i LAR-behandling. Buprenorfin har en takeffekt på respirasjonsdemping (12). Doseresponskurven ved bruk av metadon er lineær, det vil si at effekten av metadon øker med økt dosering. Når det gjelder buprenorfin, er dose-responskurven avflatende over en viss dose. I høye doser gir derfor buprenorfin mindre grad av respirasjonsdemping enn metadon, noe som gjør at overdoserisikoen er lavere med buprenorfin enn med metadon. Buprenorfin monopreparat finnes som resoritablett, som administreres sublingvalt for oppsuging gjennom munnslimhinnen. Buprenorfin finnes også som kombinasjonspreparatet Suboxone ${ }^{\circledR}$, som inneholder buprenorfin og nalokson i en 4:1-ratio.

Gjennomsnittlig daglig dosering er 13-15 mg. Buprenorfin kan på grunn av oppsugingstiden være lettere å lure unna enn metadon, selv om inntaket er overvåket. Tabletter kan lett plasseres et annet sted i munnen enn under tungen (1), for så å tas ut når observasjonstiden er over. Det er vanskeligere å lure unna metadon siden metadon drikkes.

\section{三 «De ulike LAR-legemidlene har sine fordeler og ulemper som sykepleiere må kjenne til.»}

Formålet med Suboxone ${ }^{\circledR}$ er å redusere risiko for

injisering og lekkasje til det illegale markedet (12).

Hvis Suboxone ${ }^{\circledR}$ injiseres, vil nalokson kunne

blokkere den euforiske effekten av buprenorfin og fremskynde abstinensreaksjoner, mens nalokson i hovedsak er inaktiv ved sublingval administrasjon (4). Suboxone ${ }^{\circledR}$ er derfor ofte førstevalg til LAR-pasienter som har pågående rusmiddelbruk. 
Samtidig kan det se ut som naloksonkomponenten i

Suboxone ${ }^{\circledR}$ ikke reduserer den euforiske effekten av buprenorfin i særlig grad hvis Suboxone ${ }^{\circledR}$ injiseres eller sniffes av personer som ennå ikke har utviklet toleranse for opioider $(4,8)$. Man unngår derfor ikke helt problematikken rundt lekkasje og illegal bruk (3).

Suboxone ${ }^{\circledR}$ prises likevel lavere på det illegale markedet enn buprenorfin monopreparat, og regnes som noe mindre attraktivt $(5,8,21)$. Suboxone ${ }^{\circledR}$ finnes både som sublingval tablett og film. Lekkasje og injisering av Suboxone ${ }^{\circledR}$ film ser ut til å være tilsvarende Suboxone ${ }^{\circledR}$ tablett og metadon, men lavere enn ved bruk av buprenorfin monopreparat (22). Suboxone ${ }^{\circledR}$ film kan være bedre til å forebygge lekkasje enn Suboxone ${ }^{\circledR}$ tabletter når inntaket er overvåket, fordi filmen fester seg raskt og løses opp, og dermed er vanskelig å ta ut eller flytte når den først er administrert (23).

\section{三 «Verdens helseorganisasjon anbefaler metadon som førstevalg $i$ substitusjonsbehandling.»}

Verdens helseorganisasjon anbefaler metadon som førstevalg i substitusjonsbehandling, blant annet på grunn av kost-nyttevurderinger og erfaringer knyttet til lekkasje og illegal omsetning av buprenorfin. Metadon doseres som regel en gang i døgnet og inntas vanligvis som mikstur. Gjennomsnittlig daglig dosering av metadon i Norge er $93 \mathrm{mg}$ (14). I noen land tynnes metadon ut for å redusere risiko for injisering (3). Fordeler ved valg av metadon må veies opp mot fare for overdose ved illegal bruk (5).

Launonen og kolleger (6) fant at buprenorfindoser på under 9 mg/dag kan øke risiko for lekkasje. Årsaken er at subterapeutisk dosering øker risikoen for tilbakefall, som igjen øker risiko for å selge eller gi bort hele eller deler av dosen. Andre studier har ikke funnet denne sammenhengen mellom lav dosering og lekkasje (5). 
Sykepleiere bør, sammen med lege, være oppmerksomme på de LAR-pasientene som har lav dosering for å sikre riktig dose og optimal behandling (6). For å redusere risiko for rusmiddelbruk er det anbefalt at buprenorfin ikke doseres under 12 mg/dag (14). I valg av LAR-legemiddel må det gjøres en helhetsvurdering ut fra pasientens situasjon og ønsker, legemidlenes virkning og bivirkningsprofil, hvilke utleveringsalternativer som finnes, og pasientens rusmestring.

\section{Kontroll versus tilgjengelighet}

Kontrolltiltak som overvåket inntak er ment å hindre at LAR-legemidlene inntas av andre enn pasienten selv eller i strid med legens forskrivning (13). Regelmessig oppmøte for overvåket inntak av LAR-legemidler er vanlig. I 2016 var gjennomsnittlig utlevering i Norge 3,8 ganger i uken. 51 prosent av pasientene fikk LARlegemiddelet utlevert på apotek. Resten fikk LARlegemidlene utlevert av kommunale tjenester, ved egne LAR-sentre, institusjoner eller fengsel (14).

\section{三 «Regelmessig oppmøte for overvåket inntak av LAR-legemidler er vanlig.»}

Det er en balansegang mellom den godt dokumenterte nytten av substitusjonslegemidlene og samfunnets behov for kontroll for å unngå lekkasje (12). Verdens helseorganisasjon anbefaler at alle pasienter skal ha overvåket inntak av substitusjonslegemidlene i starten av behandlingen, og at pasienter kan få «ta-medhjem»-doser når de viser stabilitet (1). Dette gjenspeiles også i den norske LAR-retningslinjen.

Nøkkelelementer ved stabilitet er at pasienten bør ha bolig, arbeid, ikke være avhengig av flere rusmidler og ha sluttet å injisere (1). Litteraturen er relativt samstemt i at overvåket inntak vil kunne redusere lekkasje, spesielt i begynnelsen av behandlingen og for pasienter som ikke er stabile $(1,3,24)$. 


\section{«Mange pasienter opplever kontrolltiltakene som nedverdigende.»}

Samtidig understreker Verdens helseorganisasjon at daglig overvåket inntak av substitusjonslegemidlene er svært inngripende, og evidensgrunnlaget er lavt (1).

Strenge kontrollrutiner kan medføre høyere terskel for enkelte til å søke LAR, og gi større frafall fra behandling $(1,16)$, noe som ikke er ønskelig. Mange pasienter opplever kontrolltiltakene som nedverdigende $(20,21)$, og strenge kontrollrutiner kan begrense muligheten for rehabilitering og arbeid (9). Økt kontroll er også ressurskrevende (1, 6, 20). Det er ikke enkelt å finne den riktige balansen mellom kontroll og tilgjengelighet, og det er et dilemma med både en faglig og etisk side. Det er usikkert om strengere kontroll enn vi har i dag, vil kunne redusere lekkasje i særlig grad (6). Sykepleiere må tematisere balansen mellom kontroll og tilgjengelighet, og løsningen må finnes i samarbeidet med den enkelte pasient.

\section{Helhetlig behandling forebygger lekkasje}

God klinisk praksis, sammen med kunnskap om lekkasjeproblematikk og hvordan dette kan forebygges, er viktig (15). Leger som forskriver LARlegemidler, må ha kunnskap om trygg forskrivning av opioider. Dette inkluderer blant annet grundig vurdering ved oppstart, og regelmessig oppfølging av pasienten for vurdering av stabilitet og effekt av behandlingen (3). Hvor mye av oppfølgingen sykepleiere kan gjøre, vil avhenge av stilling, kompetanse og erfaring. Bruk av urinprøver og uanmeldt tilbakekallelse for opptelling av medikamentene kan være måter å følge opp pasienter som får «ta-med-hjem»-doser $(3,10)$. Helsepersonell bør også samarbeide med utleverende instans, hvor eventuelle uteblivelser og klinisk vurdering av pasientens rusmestring tematiseres (1). 


\section{三 «Pasientene bør få opplæring i sikker bruk, oppbevaring og eventuell kassering av legemidlene.»}

Pasientene bør få opplæring i sikker bruk, oppbevaring og eventuell kassering av legemidlene $(3,11)$.

Samtidig er informasjon og undervisning alene ikke nok til å endre pasienters normer og atferd (20). For å redusere lekkasje og illegal bruk av LAR-legemidler bør sykepleiere fokusere på tiltak for å redusere eller stoppe pågående rusmiddelbruk, og fokusere på pasienters psykososiale situasjon (5). Det gjelder spesielt de pasientene som injiserer $(6,25)$.

Det å bistå pasienter med å bryte med et kriminelt miljø og legge til rette for mulighet til arbeid eller aktivitet kan gi mulighet for nytt sosialt nettverk, noe som igjen kan bidra til å redusere lekkasje og illegal bruk $(5,20)$. Sykepleiere og annet helsepersonell bør være oppmerksomme på pasienters egne strategier for å unngå lekkasje, som for eksempel å bytte apotek eller tidspunkt for å unngå å møte potensielle kjøpere (7). Respekt for pasientenes erfaringer kan gi økt pasientfornøydhet, som også kan forebygge lekkasje (20).

På systemnivå er god tilgang til substitusjonsbehandling viktig for å redusere etterspørselen av illegale LAR-legemidler $(5,20)$. Verdens helseorganisasjon anbefaler at nytte- og skadeperspektivet ved substitusjonsbehandling bør evalueres jevnlig, inkludert overvåkning av omfanget av lekkasje (1). Dette gjøres blant annet i Bergen. Føre var-rapporten, som kommer ut to ganger i året, gir oversikt over rusmiddeltrender, inkludert tilgjengelighet av LAR-legemidler i rusmiljøene (26). 
- ha et helhetlig perspektiv på LAR-behandling

- ha kunnskap om lekkasje

- ha oppdatert kunnskap om legemidlene

- formidle endringer i pasienters helsetilstand og rusmestring til forskrivende lege

- ha spesiell oppmerksomhet på LAR-pasienter som har lav dosering

- følge opp pasienter som får «ta-med-hjem»-doser

- fokusere på tiltak for å stoppe pågående rusmiddelbruk

- fokusere på pasienters psykososiale situasjon

\section{Kliniske implikasjoner}

Det kan være mange ulike årsaker og motiver for lekkasje og illegal bruk av LAR-legemidler. Selv om kontrolltiltak som overvåket inntak av LAR-legemidler ofte vektlegges, er det viktig å finne en balanse mellom tilgjengelighet og kontroll.

Sykepleiere må ha gode kunnskaper om fordeler og ulemper ved de ulike LAR-legemidlene, og ha et helhetlig perspektiv på behandling for å forebygge lekkasje. For å kunne fange opp endringer er regelmessig oppfølging og klinisk vurdering av de pasientene som får «ta-med-hjem»-doser, anbefalt. På systemnivå bør flere helseforetak utvikle systemer som gir oversikt over rusmiddeltrender og lekkasje av LAR-legemidler lokalt.

\section{Referanser}

1. WHO. Guidelines for the psychosocially assisted pharmacological treatment of opioid dependence [internett]. World Health Organization; 2009 [sitert 08.05.2015]. Tilgjengelig fra: http://www.who.int/substance_abuse/activities/treatment_opioid_dependence/en/ 
2. Degenhardt L, Bucello C, Mathers B, Briegleb C, Ali H, Hickman M, et al. Mortality among regular or dependent users of heroin and other opioids: a systematic review and meta-analysis of cohort studies. Addiction. 2011;106(1):32-51.

3. EMCDDA. Perspectives on drugs: strategies to prevent diversion of opioid substitution treatment medications [internett]. Lisboa: European Monitoring Centre for Drugs and Drug Addiction; 2016 [oppdatert 31.05.2016; sitert 19.03.2018]. Tilgjengelig fra: http://www.emcdda.europa.eu/topics/pods/preventingdiversion-of-opioid-substitution-treatment_en

4. Yokell MA, Zaller ND, Green TC, Rich JD. Buprenorphine and Buprenorphine/Naloxone diversion, misuse, and illicit use: an international review. Curr Drug Abuse Rev. 2011;4(1):28-41.

5. Johnsen B, Richert T. Diversion of methadone and buprenorphine by patients in opioid substitution treatment in Sweden: prevalence estimates and risk factors. Int J Drug Policy. 2015;26(2):183-90.

6. Launonen E, Alho H, Kotovirta E, Wallace I, Simojoki K. Diversion of opioid maintenance treatment medications and predictors for diversion among Finnish maintenance treatment patients. Int J Drug Policy. 2015;26(9):875-82.

7. Havnes IA, Clausen T, Middelthon AL. «Diversion» of methadone or buprenorphine: «harm» versus «helping». Harm Reduction Journal. 2013;10(24).

8. Soyka M. Buprenorphine use and risk of abuse and diversion. Advances in Pharmacoepidemiology and Drug Safety. 2014;3(1). 
9. Dale-Perera A, Goulao J, Stöver H. Quality of care provided to patients receiving opioid maintenance treatment in Europe: results from the EQUATOR analysis. Heroin Addiction and Related Clinical Problems. 2012;14(4):23-38.

10. Registered nurses' association of Ontario. Best practice guidelines: supporting clients on methadone maintenance treatment [internett]. Ontario: RNAO; 2009 [sitert 08.03.2015]. Tilgjengelig fra: http://rnao.ca/bpg/guidelines/supporting-clients$\underline{\text { methadone-maintenance-treatment }}$

11. Manworren RC, Gilson AM. Nurses' role in preventing prescription opioid diversion. The American Journal of Nursing. 2015;115(8):34-40.

12. Helsedirektoratet. Nasjonal retningslinje for legemiddelassistert rehabilitering ved opioidavhengighet [internett]. Oslo: Helsedirektoratet; 2010 [oppdatert 22.09.2014; sitert 19.01.2015]. Tilgjengelig fra: https://helsedirektoratet.no/retningslinjer/nasjonalretningslinje-for-legemiddelassistert-rehabiliteringved-opioidavhengighet

13. Forskrift 18. desember 2009 nr. 1641 om legemiddelassistert rehabilitering (LAR-forskriften). Tilgjengelig fra: http://lovdata.no/forskrift/2009-12$\underline{18-1641}$ (nedlastet 19.01.2015).

14. Waal H, Bussesund K, Clausen T, Skeie I, Håseth A, Lillevold PH. Statusrapport 2016. Er kvalitetsforbedring nå viktigere enn kapasitetsutvikling? Oslo: Actis - Rusfeltets samarbeidsorgan; 2017. Tilgjengelig fra: http://www.med.uio.no/klinmed/forskning/sentre/seraf/publikasjoner/rapporter/2017/serafrapport-nr-2-2017-statusrapport-2016.pdf (nedlastet 01.03.2018). 
15. Europeisk overvåkningssenter for narkotika og

narkotikamisbruk. Europeisk narkotikarapport 2017:

trender og utviklinger. Belgia: Europeisk

overvåkningssenter; 2017. Tilgjengelig fra:

http://www.emcdda.europa.eu/system/files/publications/4541/TDAT17001NON.pdf

(nedlastet 24.03.2018).

16. Bretteville-Jensen AL, Lillehagen M, Gjersing L, Andreas JB. Illicit use of opioid substitution drugs: prevalence, user characteristics, and the association with non-fatal overdoses. Drug and Alcohol Depend. 2014;147:89-96.

17. Richert T, Johnsen B. Long-term self-treatment with methadone or buprenorphine as a response to barriers to opioid substitution treatment: the case of Sweden. Harm Reduct J. 2015;12(12):1-14.

18. Gjersing L, Sandøy TA. Narkotikabruk på gateplan i syv norske byer. Oslo: Statens institutt for rusmiddelforskning; 2014.

19. Johnson B, Richert T. Diversion of methadone and buprenorphine from opioid substitution treatment: patients who regularly sell or share their medication. $\mathrm{J}$ Addict Dis. 2015;34(1):1-17.

20. Johnson B, Richert T. Diversion of methadone and buprenorphine from opioid substitution treatment: the importance of patients' attitudes and norms. J Subst Abuse Treat. 2015;54:50-5.

21. Lundeberg IR, Mjåland K. Åpne russcener i Bergen etter stengningen av Nygårdsparken: en studie av strategi, tiltak og brukererfaringer. Bergen:

Universitetet i Bergen; 2017.

22. Larance B, Lintzeris N, Ali R, Dietze P, Mattick R, Jenkinson R, et al. The diversion and injection of a buprenorphine-naloxone soluble film formulation. Drug Alcohol Depend. 2014;136:21-7. 
23. Rosenthal RN, Goradia VV. Advances in the delivery of buprenorphine for opioid dependence.

Drug design, development and therapy. 2017;11:2493505.

24. Wright N, D’Agnone O, Krajci P, Littlewood $\mathrm{R}$, Alho H, Reimer J, et al. Addressing misuse and diversion of opioid substitution medication: guidance based on systematic evidence review and real-world experience. Journal of Public Health.

2016;38(3):e368-e74.

25. Launonen E, Wallace I, Kotovirta E, Alho H, Simojoki K. Factors associated with non-adherence and misuse of opioid maintenance treatment medications and intoxicating drugs among Finnish maintenance treatment patients. Drug Alcohol Depend. 2016;162:227-35.

26. Knoff RV, Flesland L. Føre var - Rustrender i Bergen 02/17. Bergen: Stiftelsen Bergensklinikkene; 2017. Tilgjengelig fra:

http://korus.azurewebsites.net/wpcontent/uploads/2017/12/fore-var-host-2017.pdf (nedlastet 01.04.2018). 